\title{
Research on the Coupling Mechanism between Urban Economic Heat Island and Urban Service Industry
}

\author{
Jun XU* \\ Business School \\ Jiangsu Normal University \\ Xuzhou China \\ lmmxjxj@163.com
}

\author{
Xingcheng GE \\ Business School \\ Jiangsu Normal University \\ Xuzhou China \\ 2269098517@qq.com
}

\begin{abstract}
In recent years, the rapid progress of urban service industry in our country makes it play a more and more important role in the economic development and modernization of our country. It is an important symbol to measure the socialization of production and the development level of market economy in a country or region. The development of urban service industry has promoted the emergence of urban economic heat island, and it has become a trend of integration with urban service industry. Therefore, the connotation of urban service industry and urban economic heat island is defined and the coupling mechanism of urban economic heat island and urban service industry is established from the current situation of the development of urban service industry in China. Finally, some suggestions for the development of urban service industry are put forward.
\end{abstract}

Keywords-Urban Economic Heat Island; Urban Service Industry; Coupling mechanism; Competitiveness

\section{INTRODUCTION}

With the rapid development of economy and the continuous progress of society, the world economy is gradually developing towards the direction of integration; the scale of enterprise operation is expanding; the degree of specialization is becoming higher and higher; enterprises are paying more and more attention to the development of service industry ${ }^{[1]}$. In October 2015, the National "Thirteenth Five-Year Plan for the Development of the Service Industry" proposed "speed up the development of the modern service industry, expand the opening up of the service industry, optimize the environment for the development of the service industry; promote the specialization and high-end extension of the value chain of producer services and the shift of living services to fine and high-quality ones.” In October 2017, the 19th National Congress of the CPC pointed out: "support the optimization and upgrading of traditional industries, accelerate the development of modern service industries, and aim at raising the level of international standards.” Modern service industry plays an important role in the economic and social development, and it is the key choice to seize the commanding point of industrial competition. In the new normal period of economic development, our country pays more and more attention to the service industry. The study of the coupling mechanism between urban economic heat island and urban service industry has important practical significance for the sustainable development of urban service industry.

Therefore, this paper tries to define the connotation of urban economic heat island, through analyzing the coupling mechanism between urban economic heat island and urban service industry, establishes the coupling model of urban economic heat island and urban service industry, and puts forward the corresponding countermeasures and suggestions in order to provide theoretical guidance for the development of urban service industry.

\section{The Coupling Connotation Of Urban Economic Heat ISLAND AND URBAN SERVICE INDUSTRY}

\section{A. The connotation of Urban Service Industry}

The urban service industry is different from the service industry. It is found that the research on urban service industry is more about the modern service industry with certain technological content in the city. Therefore, the definition of urban service industry in this paper is mainly based on the modern service industry.

Urban service industry means that with the development of information technology and the emergence of knowledge economy, new technology, new business forms and new service modes are used to upgrade and transform the traditional service industry, create demand, and promote consumption and it can provide the community with high value-added, high level, high standards of production services and living services. Urban service industry usually includes two aspects: one is to emphasize that urban service industry belongs to technology-intensive industry, relying on the application of information technology to achieve specialization, high level and high efficiency of service; the second is to highlight the more capital investment in urban services, higher value-added and the industry involved in a wide range of areas. Urban service industry has the characteristics of high technology, high capital, high benefit, high driving force, low resource consumption and low environmental pollution ${ }^{[2]}$.

With the rapid development of economy, the continuous optimization of economic structure and the improvement of residents' income, more and more attention has been paid to 
the development of urban service industry, which has become an important part of promoting China's economic development. In recent years, the development of urban service industry in our country is more and more considerable, and it has been in a state of continuous progress, which is mainly reflected in the following two aspects:

- Continuous optimization of the internal structure. The rapid development of urban service industry has led to the emergence of many new industries, so that the internal structure of the service industry has been constantly optimized, and the level of specialization has been constantly improved. In 2015, the growth rate of transportation, storage and post industry, wholesale and retail trade, accommodation and catering industry, financial industry and real estate industry were $4.6 \%$, $6.1 \%, 6.2 \%, 15.9 \%$ and $3.8 \%$, respectively; these sectors grew by $6.5 \%, 6.7 \%, 6.9 \%, 5.7 \%$ and $8.6 \%$ in 2016. All these data fully show that the internal structure of urban service industry in China tends to be optimized. In 2016, the contribution rate of the tertiary industry to the economy was $58.2 \%$, far exceeding that of the primary and secondary industries; among them, the value-added of modern service industries, composed of information transmission, software and information services, finance, real estate, scientific research and technical services, education, health and social work, culture, sports and entertainment, accounted for a percentage of the total was $30.1 \%$. The development of urban service industry has made remarkable progress.

- Creating a lot of demand for jobs. In recent years, the rapid development of knowledge-intensive industries has led to the employment growth of urban service industry. According to statistics, at the end of 2016, china's tertiary industry employed 337.57 million people, 9.18 million more than in 2015, an increase of 2.8 percent over the same period last year. The number of employees employed in the modern service industry reached 54.61 million, an increase of $2.4 \%$ over the previous year and the increase is more obvious. Among them, the number of people engaged in scientific research and technical services has reached 4.196 million, and the number of people engaged in real estate has reached 4.317 million; the number of employees in finance, information transmission, software and information technology services, leasing and business services also increased by 587000, 142000 and 144000 over the previous year, respectively, up 9.62 percent, 4.06 percent and 3.04 percent; there was also a marked increase in employment in residential services, repairs and other services, health and social work, culture, sports and entertainment compared to last year. The above data fully show that the development of urban service industry has become an important channel to solve the employment problem.

Although great achievements have been made in the development of the urban service industry in China, there are still some problems. The development level of urban service industry is unbalanced. For example, the development of service industry in first-tier cities such as Beijing, Shanghai and Guangzhou has promoted the development and agglomeration of their economic level to a great extent. While some second- and third-tier cities such as Xuzhou and Guiyang, the development of urban service industry does not play a good role in promoting economic growth. In addition, the low level of urban service industry, the slow development of emerging industries, the distribution of the service industry and other issues, also become important factors restricting the development of urban service industry in our country ${ }^{[3]}$. Therefore, this paper tries to discuss the coupling mechanism between urban economic heat island and urban service industry; constructs the conceptual model of the mutual integration and development of urban economic heat island and urban service industry, and then puts forward some policy suggestions to promote urban service industry.

\section{B. Connotation and characteristics of Urban Economic Heat Island}

At present, there are few research results about urban economic heat island at home and abroad, and even less about urban economic heat island. In the existing literature, foreign scholar Hirschman pointed out that "economic take-off is impossible to appear in multiple regions at the same time and once a region has achieved economic take-off, there will be a strong force to promote economic growth in the region around its origin" " ${ }^{[4]}$.This view laid the foundation for the development of urban economic heat island theory. Wang Kun (2006) put forward the concept of urban economic heat island (UHI) earlier "these areas of economic activity, similar to growth poles, are called economic heat islands" and studied it $^{[5]}$. P. Ma, W.X. Li (2010) pointed out that due to the spatial concentration of scientific and technological innovation and social change, and the very slow diffusion rate among regions, for a long time, economic growth has been characterized by regional concentration. It deepens the theory of urban economic heat island ${ }^{[6]}$.

Combined with scholars' research on urban economic heat island, in this paper, urban economic heat island specifically refers to the energy of some economic material elements, starts from a central point and through the release of energy and strong fusion, it causes a chain reaction of economic and social activities of the same type of material elements in the surrounding area of a city, thus producing the phenomenon that the economic potential energy of the city center is obviously higher than that of the surrounding area. The main function of urban economic heat island is to trigger a large agglomeration of urban economy; form an economic energy gathering area; release energy, and radiate the development of the city and society to the greatest extent.

III. ANAlysis on the COUPLING MeChanism BetWeEN URBAN ECONOMIC HeAt IsLAND AND URBAN SERVICE INDUSTRY

\section{A. The effect Mechanism of Urban Service Industry Development on Urban Economic Heat Island effect}

After the service industry develops into a certain scale, it will produce the agglomeration effect of the urban service industry, and the agglomeration effect is the main motive force of the urban economic heat island. That is, the agglomeration effect of urban service industry can bring economies of scale 
within enterprises and industries, as well as regional economies of scope to promote the agglomeration of urban economy, resulting in urban economic heat island effect.

- The agglomeration of urban service industry promotes the agglomeration of urban economy by promoting the competitiveness of service enterprises. On the one hand, the agglomeration effect of urban service industry is conducive to enterprises to obtain internal economies of scale, thereby promoting the competitiveness of urban service industry. On the other hand, the agglomeration effect of urban service industry is also conducive to enhance the competitiveness of manufacturing enterprises. The agglomeration of urban service industry, especially the agglomeration of producer services, enables manufacturing enterprises in the city to obtain more rapid and convenient services, and thus enhance their competitiveness.

- Urban service industry promotes the agglomeration of urban economy by improving the competitiveness of service industry, and produces urban economic heat island effect. The division of labor and cooperation as well as the level of specialization in urban service industry promotes the emergence of external economies of scale and knowledge spillover and the agglomeration of urban service industry is conducive to enhance the competitiveness of industries in the region. The development of industry is the main driving force of urban economic agglomeration, and the promotion of industrial economic strength can promote the generation of urban economic heat island effect.

- The agglomeration of urban service industry promotes the agglomeration of urban economy by promoting the regional competitiveness and produces the urban economic heat island effect. The agglomeration of urban service industry is conducive to the promotion of regional innovation ability and thus promotes the agglomeration of urban economy, resulting in the urban economic heat island effect. The agglomeration of urban service industry promotes the agglomeration of urban economy through the advantages of regional product brands. On the one hand, the agglomeration effect of urban service industry is conducive to the formation of regional brands. On the other hand, building regional brand is beneficial to the development of urban economy. Therefore, the agglomeration effect of urban service industry is beneficial to the formation of regional brand, and the creation of regional brand is the main driving force to promote the agglomeration of urban economy. Besides, the development of urban service industry is beneficial to the agglomeration of urban economy and then produces the urban economic heat island effect.

\section{B. The supporting response of Urban Economic Heat Island to the Development of Urban Service Industry}

The urban economic heat island effect will bring two kinds of economic effects: one is the increasing benefit brought by the specialization of urban service industry; the other is the agglomeration economy brought by the agglomeration of factors. These two economic effects lead to the agglomeration of economic activities in the city.

- The agglomeration of labor force leads to the agglomeration of urban service industry. On the one hand, with the gradual increase of urban population, trade, catering, real estate, education, culture and sports, health care and other life services will inevitably have a huge demand. The process of urbanization development already includes the increase of urban population and urban economic heat island effect is bound to create more employment demand and attract more labor force in the city. Therefore, the agglomeration of labor force is conducive to the formation of large-scale demand, and large-scale demand is a necessary condition for the agglomeration of urban service industry. On the other hand, urban service industry as a labor-intensive industry, the agglomeration of urban service industry needs more labor resources. Therefore, the agglomeration of labor brought by urban economic heat island effect will promote the agglomeration and development of urban service industry.

- The agglomeration of industry brings about the agglomeration of urban service industry. As an important resource turnover center, allocation center, material distribution and circulation center, information exchange and processing center and so on, with the agglomeration of urban economy, the cities will inevitably bring about the gathering of elements. That is, whether physical capital or human capital will continue to gather in the city. The agglomeration of factors will often bring about the agglomeration of various economic activities in cities, and the agglomeration of various economic activities will inevitably require the support of productive services such as finance, insurance, communications, transportation, storage, legal, and technical services. This, in turn, will attract more service industries to gather in cities. Therefore, with the agglomeration of urban economy, all kinds of factors will gather rapidly in the city, which will bring about the agglomeration of various economic activities, and then promote the agglomeration and development of urban service industry.

- The location advantage of the city also provides the conditions for the agglomeration of the urban service industry. With the development of urban economy, the agglomeration of urban service industry needs large-scale infrastructure, a large number of labors and the support of the external environment, which can be provided by the city. In addition, the better the agglomeration effect of urban economy is, perfect the external environment will be, and then the urban service industry will develop faster.

\section{The Conceptual Model of the Coupling Development of Urban Economic Heat Island and Urban Service Industry}

To sum up, the urban economic heat island effect makes more and more labor force and economic activities gather to the city, and the location advantage of the city itself also provides a perfect external environment for the development 
of the urban service industry and then attracts more service industry to gather in the city. The agglomeration of urban service industry will promote the development of urban economy, and then produces the urban economic heat island effect. The emergence of urban economic heat island effect and the development of urban service industry will lead to more labors and economic activities in the urban agglomeration, and bring more geographical advantages. In this way, the development of urban economic heat island and urban service industry has formed a virtuous circle. Based on this, a conceptual model of the coupled development of urban economic heat island and urban service industry can be established, as shown in the following figure:

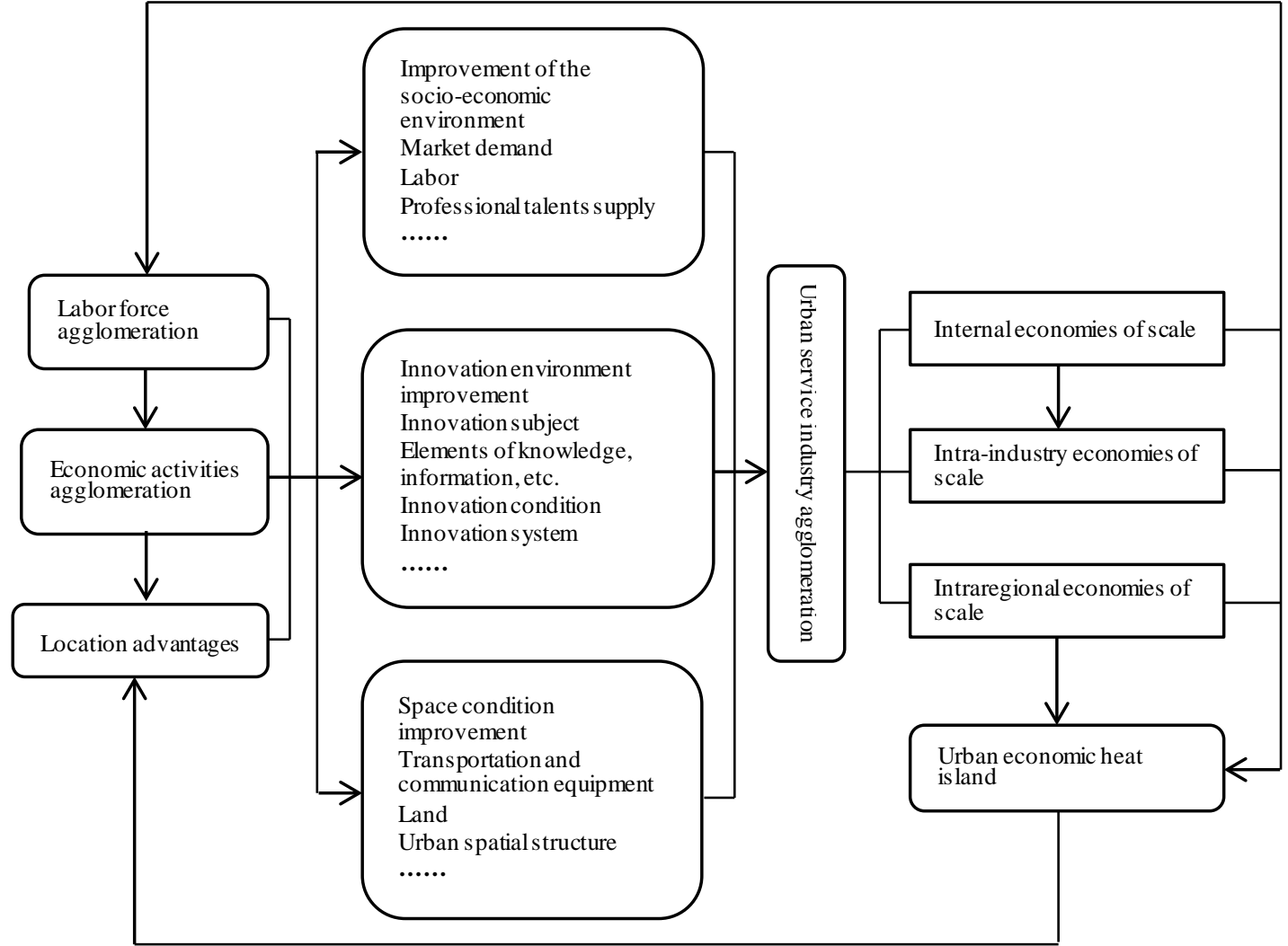

Fig. 1. Conceptual model of coupled development of urban economic heat island and urban service industry

\section{Suggestions on Sustainable Development of Urban SERVICE INDUSTRY}

It is not difficult to find that the agglomeration development of urban service industry promotes the agglomeration of urban economy and produces the urban economic heat island effect; the urban economic heat island effect makes more and more labors and economic activities gather to the city and promote the development of urban service industry. Therefore, to find a suitable and effective strategy for the development of urban service industry is very important for the progress of urban service industry and the agglomeration of urban economy. The following are three suggestions to promote the development of urban service industry.

\section{A. Encouraging Innovation and attaching importance to the Development of Urban Service Industry to promote Urban Economic agglomeration}

To promote the sustainable development of urban service industry, we should pay more attention to the role of innovation. It is necessary to strengthen the coordination and alliance among urban service industries; plan the development of urban service industry together; establish a profit sharing mechanism among enterprises, and form an interest community. It is necessary to strengthen the interaction with scientific research institutes and universities; promote the exchange of professional knowledge; transform the specialized knowledge into efficient productivity; improve the innovation and competitiveness of urban service industry, and then promote the agglomeration of urban economy. At the same time, we should also improve the scientific and technological level of urban service industry, which can save human and material resources to a certain extent, improve the quality of service, and it also play a great role in promoting the development of urban service industry.

\section{B. Strengthening the cultivation of Professional talents}

Professionals are also essential to the development of urban services. Especially in the context of the economy into the new normal, many emerging service industries emerged and there are a large number of job vacancies, at this time; the demand for professional personnel also greatly increased. Therefore, only by training professional service personnel actively, can we adapt to the needs of social development and promote the development of urban service industry. On the contrary, if there are a large number of talent shortages, it will not only cause huge losses to the development of urban 
service industry, but also hinder the agglomeration of urban economy.

\section{Creating a good market environment}

Good market environment plays a decisive role in the coupling development between urban economic heat island and urban service industry. Therefore, the relevant departments should improve the laws and regulations on the sustainable development of urban service industry, in order to restrain the non-standard behavior between the service industries. The government should formulate the incentive policy to attract more service industry to gather in the city and promote the development of the urban service industry. In addition, the market departments should strengthen supervision, build a good political environment, talent environment and social environment, and then promote the coupled development of urban service industry and urban economic heat island.

\section{CONCLUSION}

At present, the global industrial structure has begun to change, gradually transforming from an industrial economy to a service-oriented economy, and develops the service industry into an important pillar industry of a country. It is of practical significance to study the coupling relationship between urban economic heat island and urban service industry. Therefore, this paper first tries to define the connotation of urban economic heat island and urban service industry, and study the development status of urban service industry. Then it discusses the coupling mechanism between urban economic heat island and urban service industry in order to provide a new perspective for the integration and development of the two. Finally, it puts forward some policy recommendations for the development of urban service industry.

\section{ACKNOWLEDGMENT}

This work was supported by Postgraduate Research \& Practice Innovation Program of Jiangsu Province (No. KYCX18_2066), National Social Science Foundation (No. 16BJY042), Jiangsu qinglan project (Teacher Sue (2017) N0. 15) and Jiangsu education department university philosophy and social science project (No. 2018SJZDI090)

\section{REFERENCES}

[1] A.L. Jiao, Research on the Interactive Development relationship between producer Services and Manufacturing Industry in China, Commercial Times, vol.17, pp. 123-124, June 2014. (In Chinese)

[2] H.W. Lu, Research on the path of Modern Service Industry promoting the Transformation of Hubei's Economic Development Mode, Contemporary Economics, vol.2, pp. 86-89, February 2014. (In Chinese)

[3] X.Y. Yue, Research on the present situation Evaluation and Development Strategy of Modern Service Industry in Henan Province, Shandong Textile Economy, vol.3, pp. 10-12, April 2016. (In Chinese)

[4] W.D. Tao, Development Economics, Chengdu: Sichuan people's Publishing House, 1992 (In Chinese)

[5] K. Wang, A preliminary study on the Economic Heat Island effect, Coal Economic Research, vol.3, pp. 31-33, April 2006. (In Chinese)

[6] P. Ma and W.X. Li, An empirical study on Spatial agglomeration of Service Industry and Urban Economic Development, Journal of Zhongnan University of Economics and Law, vol.3, pp. 87-93+144, April 2010. (In Chinese) 